\title{
DETERMINANTES DA INOVAÇÃO: UM ESTUDO EMPÍRICO EM INDÚSTRIAS DE CONFECÇÃO DO MUNICÍPIO DE FORMIGA/MG
}

Bruno César Melo Moreira ${ }^{1}$ Everaldo Hipólito da Silva ${ }^{2}$ Lélis Pedro de Andrade ${ }^{3}$ Adriano Olímpio Tonelli ${ }^{4}$

\section{Resumo}

O artigo apresenta a análise das empresas de confecção que constituem o Arranjo Produtivo Local (APL) de confecções da cidade de Formiga (MG), setor este que se caracteriza como o maior dinamizador da economia do município. $\mathrm{O}$ estudo objetiva identificar os fatores determinantes da inovação nas referidas empresas por meio de um survey aplicado com seus principais gestores. Os resultados mostram que a prática da inovação nas empresas é entendida apenas como um meio para a redução de custos de produção. Essas evidências sugerem que ainda não há um aproveitamento de todo o potencial inovativo das organizações, embora haja alguns traços, sobretudo de inovação de processos, em boa parte das empresas.
1 Doutor, e-mail: bruno. melo@ifmg.edu.br

2 Especialista, e-mail: everaldohs@gmail. com

3 Doutor, e-mail: lelis. pedro@ifmg.edu.br

4 Mestre, e-mail: adriano. tonelli@ifmg.edu.br

Palavras-chave: Arranjo Produtivo Local. Inovação. Competitividade. Confecção. 


\section{INTRODUÇÃO}

Por diversas vezes, o termo inovação tem estado presente nas discussões do meio acadêmico. Isto se dá em virtude de ser a inovação uma das principais ferramentas das organizações e das nações na incessante luta pelo desenvolvimento econômico (BRASIL, 2011) e por uma maior competitividade (CNI,2005; QUANDT, 2012).

Assim sendo, torna-se vital para a implementação de políticas públicas e estratégias privadas obter informações que facilitem o entendimento a respeito do processo de geração, difusão e incorporação da inovação, bem como de condições institucionais que exerçam influência sobre ela (BRASIL, 2011).

Tal reconhecimento a respeito daimportância da inovação se faz ainda mais pertinente, sobretudo no momento em que o Brasil vem perdendo competitividade frente a outras economias. De acordo como relatório do Fórum Econômico Mundial (WEF), atualmente o Brasil ocupa a $57^{\mathrm{a}}$ posição no ranking de competitividade global composto por 144 países, retrocedendo, assim, uma posição em relação ao último ano. (WEF, 2014).

A baixa competitividade brasileira é um problema a ser enfrentado continuamente, uma vez que “[...] o ganho de competitividade é fundamental para a maior inserção da indústria brasileira em mercados cada vez mais globalizados." (CNI, 2006, p. 11).

Posto isso, essa realidade se torna ainda mais factível quando se leva em conta o setor têxtil e de confecções brasileiro, que vem sofrendo com a forte disputa de mercado internacional, sobretudo com a concorrência chinesa.
Com uma indústria produtiva ancorada nos baixos custos de produção (salário e matéria-prima) e no câmbio depreciado, mas também na diversificação horizontal e vertical que preserva múltiplas atividades nessa cadeia produtiva, a China se torna cada vez mais competitiva nesse segmento.(DELGADO,2015). Aliado ao fim do Acordo de Têxteis e Vestuários (ATV) no ano de 2005, que pôs fim às restrições de importações de artigos têxteis em diversos países no mundo, incluindo os Estados Unidos, a China se torna líder mundial na produção $(43,4 \%)$ e no comércio têxtil e de confecções, com suas exportações passando de $8 \%$ do total mundial, em 1995, para cerca de 27,2\% no ano de 2006. (COSTA; ROCHA, 2009).

Nesse cenário,mesmo com um forte crescimento no consumo em todo o mundo, o Brasil vem perdendo competitividade e espaço no mercado mundial neste setor. Ao longo dos anos 2000, o país viu sua participação no comércio declinar de 0,7\%, em 1997, para 0,3\%, em 2007. (COSTA; ROCHA, 2009). Segundo os autores:

\footnotetext{
Nessa conjuntura, tornou-se fundamental para a sobrevivência das empresas da cadeia têxtil e de confecções desenvolver estratégias competitivas diferenciadas, baseadas na utilização da inovação tecnológica como um instrumento relevante para inserção no mercado mundial. (COSTA; ROCHA, 2009, p. 160).
}

É neste ambiente de alta competitividade que estão inseridas as empresas do Arranjo Produtivo Local (APL) de Confecções da cidade de Formiga/MG, batalhando incessantemente pela própria sobrevivência. 
Como já citado anteriormente, a inovação vem sendo reconhecida como um dos principais pilares resultantes de incremento na competitividade das empresas e também do desenvolvimento econômico.

Segundo um levantamento realizado pelo SEBRAE (2009), o faturamento de micro e pequenas empresas que inovaram foi o dobro daquele verificado em empresas que não passaram por processo de inovação.

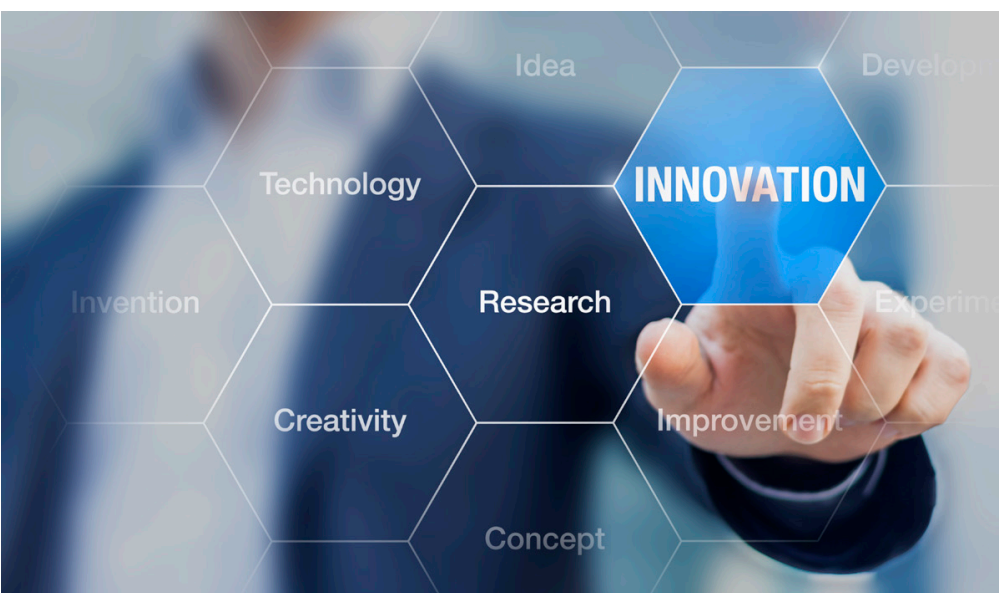

Tal fato exemplifica claramente o objetivo magno da inovação, que é melhorar o desempenho das empresas através do ganho ou manutenção de uma vantagem competitiva, seja com a mudança da curva de demanda dos produtos, ou pela alteração de sua curva de custos (OCDE,2005). Ferrel e Hartline (2009, apud ALBUQUERQUE JUNIOR; LIMA; LAZARO, 2011) destacam ainda que, se uma empresa não possui vantagem competitiva, ela e seus produtos tornam-se somente uma oferta a mais no mercado.

Corroborando esse argumento, a Pesquisa de Inovação 2011 - PINTEC ressalta que maior competitividade, maior valor agregado e abertura de novos mercados estão entre as principais consequências da inovação (BRASIL, 2011).

Ainda conforme a PINTEC 2011, os impactos inovativos podem ser percebidos e associados a diversas áreas dentro das organizações, tais como o produto, o mercado, os processos, aspectos ligados ao meio ambiente e também a regulamentações e normas. (BRASIL, 2011).

\subsection{Inovação na indústria têxtil e de confecção}

Segundo Garcia et al. (2005 apud Alvarenga et. al., 2014), um exemplo de inovação bem-sucedida na indústria têxtil é a utilização da microfibra (a partir dos anos 70) na criação de novos tecidos. Dentre outros resultados, essa inserção gerou redução de custos e novas características técnicas ao produto final.

Referente às inovações realizadas na indústria têxtile de confecções brasileiras, observa-se uma dominância em relação às inovações de processo sobre as inovações de produto (FERNANDES; CARIO, 2008).

Vale salientar que, ainda de acordo com Fernandes e Cario (2008), os fornecedores são parte primordial do processo inovativo no setor têxtil, uma vez que significativa parcela das inovações desse setor advém da aquisição de máquinas e equipamentos, bem como de novos tipos de matéria-prima.

RATIfICANDO TAL ARGUMEN-

to, Costa e Rocha (2009)

RESSALTAM QUE UMA DAS

CARACTERÍSTICAS DA CADEIA

DE TÊXTEIS E DE CONFECÇÕES

É SER CONSUMIDORA DE TEC-

NOLOGIAS, TENDO EM CONTA

QUE A MAIORIA DAS INOVAÇÕES

ACONTECEM DE FORMA EXÓ-

GENA ÀS EMPRESAS, PRINCIPAL-

MENTE VIA FORNECEDORES. 
Ainda de acordo com Fernandes e Cario (2008), devido a certa facilidade em apoderar-se de conhecimentos e informações, bem como de utilizá-los no processo produtivo das empresas, fontes, como clientes, concorrentes, feiras e exposições, dentre outras, também se tornam relevantes para a expansão de inovações no setor.
A seguir, serão apresentadas algumas das possibilidades de inovação para os principais elos do setor têxtil e de confecções, levantadas a partir de Costa e Rocha (2009), conforme apresenta o Quadro 1.

Quadro 1: Oportunidades de Inovação na Cadeia Têxtil e de Confecções
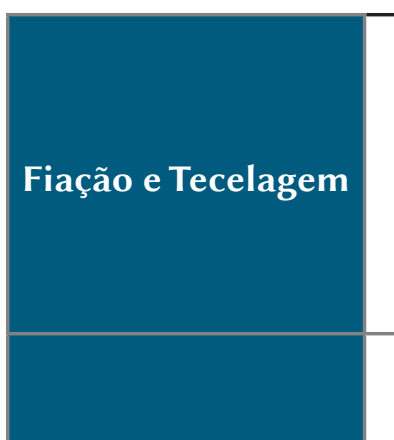

Confecção

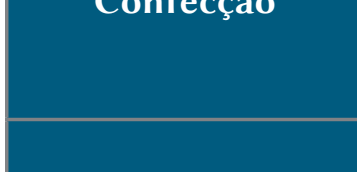

Acabamento

Possibilidade de misturar fibras naturais e químicas.

Utilização de sistemas, como o CAD/CAM (Computer Aided Design/ Computer Aided Manufacturing), para a realização de cortes e desenhos nos tecidos.

Avanços tecnológicos (área de microeletrônica).

Máquinas de costura com dispositivos eletrônicos acoplados para maior precisão no acabamento.

Utilização do sistema CAD/CAM nas fases de desenho e corte. Segmento de vestuário, oportunidade de inovação em design do produto.

Oportunidade de inovação no tratamento físico e físico-químico responsável pela aparência final do produto (lavação, tingimento, cozimento, estamparia).

Fonte: Adaptado de Costa e Rocha (2009)

Ainda concernente à implementação de inovações, o estudo de Carvalho e Serra (1999) buscou identificar as estratégias inovativas que mais se destacam na cadeia têxtil e vestuário paulista. $\mathrm{O}$ estudo dos referidos autores possibilitou identificar duas tendências principais.

A primeira, refere-se à inovação de processos e de gestão. Com foco na modernização e na relocalização,geralmente é adotada por empresas de grande porte (fornecedoras de produtos padronizados). Caracteriza-se pela modernização das plantas (importação de equipamentos de última geração), otimização dos postos de trabalho e pelo foco nas etapas de competências básicas (core competencies).
A segunda tendência enfatiza a inovação de produto por meio da diferenciação. Suas características são a ênfase na marca e no design do produto. A empresa que adota essa iniciativa não busca a produção padronizada, conseguindo assim um maior valor agregado.(CARVALHO; SERRA, 1999).

É válido salientar que o movimento de desverticalizar a produção, somado a outros fatores, como a grande proximidade entre as empresas líderes de mercado, no que se refere a máquinase equipamentos, além da crescente influência das matérias-primas e equipamentos na qualidade final do produto, têm aumentado a necessidade 
de se aprimorar a administração e a coordenação da cadeia produtiva, promovendo inovações nas áreas de informação, comunicação e logística. (COSTA; ROCHA, 2009).

\subsection{A indústria têxtil e de confecções de Minas Gerais e de Formiga}

O setor têxtil e de confecções encontrou em Minas Gerais condições propícias para que pudesse se desenvolver. Dentre elas, destacam-se a localização do Estado próximo aos principais mercados consumidores e fornecedores, bem como a abundante oferta de mão de obra, sobretudo feminina (ANDRADE, 2002 apud CUNHA, 2013).

Localizada na região centro-oeste do estado de Minas Gerais, a cidade de Formiga possui com uma população estimada para o ano de 2015 de aproximadamente 68.040 habitantes. Seu Produto Interno Bruto - PIB foi em torno de $\mathrm{R} \$ 971.253$ (em milhões de reais) no ano de 2012 (BRASIL, 2015).

O município apresenta uma população ocupada superior a 26.000 pessoas, sendo que o setor que mais emprega é o de serviços $(37,15 \%)$, seguido pelo setor industrial $(28,69 \%)$, setor de comércio
(20,27\%) e, por fim, o setor de atividades agropecuárias (13,89\%) (FORMIGA, 2015).

O setor de confecções em Formiga/MG surgiu, timidamente, na década de 1970, como fruto da reestruturação das indústrias de confecções de São Paulo e Rio de Janeiro, que, visando à redução de custos, passou a terceirizar e subcontratar pequenas empresas em cidades do interior, assim como Formiga. Porém, atualmente é grande a importância do setor para a cidade, uma vez que é considerado pelos empresários locais como um dos motores da economia formiguense. (LOPES, 2002 apud TEIXEIRA, 2012).

A importância do setor têxtil e de confecções para a cidade de Formiga fica evidente ao observarmos sua capacidade de geração de emprego e renda para o município, haja vista que, em 2013, era o setor que mais empregava individualmente ( $12 \%$ da mão de obra da cidade), representando o $3^{\circ} \mathrm{em}$ termos de renda total mensal gerada (7,5\%), ficando apenas atrás do setor de administração pública geral e de construção de rodovias e ferrovias (FUNDAÇÃO JOÃO PINHEIRO, 2016).

Tal capacidade de geração de emprego e renda e a consequente importância do setor de confecções para a cidade de Formiga podem ser melhor visualizadas com a análise da Tabela 1 , que apresenta esses dados de forma comparativa, possibilitando seu estudo de forma detalhada. 
Tabela 1: Geração de emprego e renda do setor de confecções em Formiga/MG

\begin{tabular}{|c|c|c|c|c|c|c|}
\hline Ano & $\begin{array}{c}\text { Total de } \\
\text { empregos } \\
\text { setor de } \\
\text { confecções* }\end{array}$ & $\begin{array}{c}\text { Total de } \\
\text { empregos } \\
\text { em } \\
\text { Formiga* }\end{array}$ & $\begin{array}{c}\text { Total de } \\
\text { empregos } \\
\text { setor de } \\
\text { confecções } \\
(\%)\end{array}$ & $\begin{array}{c}\text { Renda } \\
\text { mensal setor } \\
\text { confecções }^{* *}\end{array}$ & $\begin{array}{c}\text { Renda } \\
\text { mensal } \\
\text { total de } \\
\text { Formiga** }\end{array}$ & $\begin{array}{c}\text { Renda } \\
\text { mensal } \\
\text { setor } \\
\text { confecções } \\
(\%)\end{array}$ \\
\hline 2002 & 2,04 & 11,00 & $18,5 \%$ & 0,47 & 4,41 & $10,7 \%$ \\
\hline 2003 & 2,00 & 11,30 & $17,7 \%$ & 0,53 & 5,14 & $10,4 \%$ \\
\hline 2004 & 2,25 & 11,90 & $18,9 \%$ & 0,67 & 5,83 & $11,6 \%$ \\
\hline 2005 & 2,15 & 12,90 & $16,7 \%$ & 0,70 & 6,99 & $10,1 \%$ \\
\hline 2006 & 2,21 & 13,40 & $16,5 \%$ & 0,82 & 8,12 & $10,1 \%$ \\
\hline 2007 & 2,19 & 14,70 & $14,9 \%$ & 0,89 & 10,00 & $8,9 \%$ \\
\hline 2008 & 2,22 & 14,80 & $15,0 \%$ & 1,01 & 10,8 & $9,4 \%$ \\
\hline 2009 & 2,00 & 15,20 & $13,2 \%$ & 1,01 & 12,2 & $8,3 \%$ \\
\hline 2010 & 2,06 & 16,30 & $12,6 \%$ & 1,12 & 14,7 & $7,6 \%$ \\
\hline 2011 & 2,07 & 16,80 & $12,3 \%$ & 1,23 & 16,6 & $7,4 \%$ \\
\hline 2012 & 2,17 & 16,80 & $12,9 \%$ & 14,8 & 18,7 & $7,9 \%$ \\
\hline 2013 & 2,14 & 17,50 & $12,2 \%$ & 1,61 & 21,4 & $7,5 \%$ \\
\hline \multicolumn{7}{|c|}{ * em milhares } \\
\hline ** em r & de reais & & & & & \\
\hline
\end{tabular}

Fonte: Adaptado de Fundação João Pinheiro (2016)

\section{METODOLOGIA}

\subsection{Método de coleta de dados e amostra}

Esta pesquisa se propõe a analisar os fatores determinantes da inovação nas empresas que constituem o Arranjo Produtivo Local (APL) de Confecções da cidade de Formiga/ $\mathrm{MG}$, possuindo característica exploratória e descritiva,com caráter quantitativo. Quanto aos procedimentos, caracteriza-se como um survey, utilizando-se de um questionário (disposto no Apêndice A) como método de coleta de dados. O questionário construído baseou-se principalmente na Pesquisa de Inovação - PINTEC (BRASIL, 2011), bem como na Pesquisa sobre Atitudes Empresariais para Desenvolvimento 
e Inovação - PAEDI (BRASIL, 2012), e busca identificar: os tipos, características e fontes de inovação, a motivação e impactos decorrentes de sua implementação, bem como as dificuldades e obstáculos encontrados no processo inovativo.

A amostra foi não probabilística, por acessibilidade e/ou conveniência, uma vez que a pesquisa foi realizada com as empresas regularmente inscritas na Receita Estadual e filiadas ao Sindicato de Vestuário de Formiga (SINDVESF), contando com o auxílio do mesmo. A amostra total foi de 48 empresas, que é o total de empresas filiadas ao SINDVESF. Em cada uma das empresas, procedeu-se até 3 tentativas de se responder ao questionário.

\section{ANÁLISE DOS RESULTADOS}

Devido à recusa de algumas empresas em responder o questionário, o total de empresas efetivamente entrevistadas foi de 34 (70,83\% da amostra inicial). Ressalta- se que, no entanto, dentre as empresas respondentes, contou-se com a participação das duas maiores confecções da região em faturamento bruto e número de funcionários.

Após a aplicação do questionário, os resultados começam a denotar a realidade das empresas integrantes do APL de confecções de Formiga e suas principais características serão apresentadas a seguir.

Quanto ao período de existência das instituições, o estudo evidencia que 24 empresas (70,59\%) se encontram no mercado há mais de 10 anos, sendo que 7 delas estão estabelecidas há mais de 20 anos.

No tocante ao porte das organizações, constata-se o total predomínio de empresas de pequeno porte $^{1}$, haja vista que 26 delas $(76,47 \%$ do total) se enquadram nessa faixa. As organizações enquadradas como microempresas somam 7 ,

\footnotetext{
1 Vale salientar que, devido à imprecisão dos entrevistados em apontar de forma correta e segura o porte das empresas, optou-se aqui por utilizar o critério de classificação de empresas, segundo o número de funcionários, adotado pelo SEBRAE. Disponível em: <http://zip.net/bctx2Z>. Acesso em: mai. 2015.
}

representando $(20,59 \%)$ da amostra e apenas $1(2,3 \%)$ se enquadra como média empresa.

Em relação aos colaboradores das empresas, a pesquisa revelou que 29 organizações $(85,29 \%)$ contam com até 49 funcionários, outras 4 empresas possuem até 100 funcionários e apenas 1 possui mais de 100 empregados.

Outro ponto a ser considerado diz respeito à abrangência de atuação das empresas: 24 delas, $70,59 \%$, possuem como foco o mercado nacional, sendo que as demais atuam somente no município ou no mercado regional.

Uma característica importante realçada pelo estudo refere-se ao segmento das organizações pesquisadas. Grande parte das empresas pesquisadas, a saber, 27 empresas (79,41\% do total), dedicam-se ao segmento de facção, enquanto 5 empresas $(14,71 \%)$ são confecções e apenas 2 das organizações $(5,88 \%)$ são consideradas Private Label.

No tocante à inovação, a pesquisa demonstra que em 11 empresas (32,35\%) das organizações

\footnotetext{
2 Private Label: expressão em inglês que significa "etiqueta fechada", e recentemente vêm sendo usada no meio empresarial para designar aquelas empresas responsáveis pelo desenvolvimento e produção de mercadorias para marcas de terceiros. Diferentemente da confecção, a Private Label é responsável por todo o processo e não apenas por algumas etapas.
} 
pesquisadas não foi encontrada qualquer iniciativa referente ao planejamento e/ou implantação de nenhum tipo de inovação, conforme se verifica a seguir, no Gráfico 1. Considerando o perfil das empresas do município $(79,41 \%$ do total dedicam-se ao segmento de facção), este resultado se mostra coerente.

Chama atenção o fato de $65,22 \%$ das empresas que implementaram algum tipo de inovação utilizaram-se de recursos próprios para viabilizar seus projetos. As demais contaram com linhas específicas de crédito para esse fim, oriundas, por exemplo, do Banco Nacional de Desenvolvimento Econômico e Social - BNDES.

\section{ESTUDO EVIDENCIA,}

AINDA, QUE DENTRE OS

TRÊS TIPOS DE INOVAÇÃO

PRESENTES NAS EMPRESAS

DO APL DE CONFECÇÕES DE

FORMIGA, HÁ UM COMPLETO

DOMÍNIO DA INOVAÇÃO DE

Processo (58,82\%), SOBRE A

InOVAÇÃo de Produto (3\%)

E INOVAÇÃO DE ESTRUTURA

Organizacional $(11,76 \%)$,

TAL QUAL É APRESENTADO

PELO GrÁfico 1.

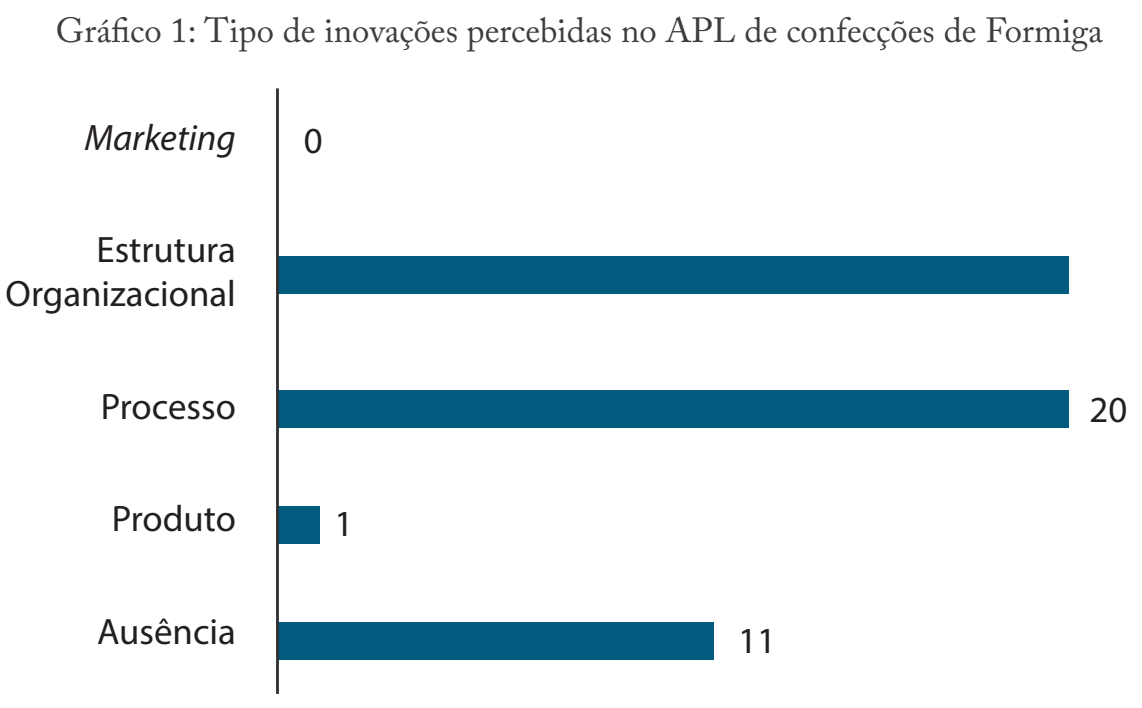

Fonte: Dos autores (2016)

Tal fato se explica, em parte, pelo argumento já anteriormente citado, que é a concentração no APL de empresas destinadas ao ramo de facção, uma vez que, sendo elas responsáveis apenas pela parte operacional de montagem das peças, ficam impossibilitadas de realizar qualquer alteração no seu produto final.

É importante ressaltar que esse mesmo argumento (concentração de facções), pode contribuir também para a ausência de Inovações em Marketing nas empresas pesquisadas.

Outro aspecto importante a ser considerado e que corrobora com a hegemonia do tópico Inovação de Processo sobre os demais pode ser visualizado no Gráfico 2, que apresenta as principais atividades de inovação presentes nas organizações do APL de confecções de Formiga. 
Gráfico 2: Atividades de inovação apresentadas pelas empresas analisadas

Aquisição de máquinas

e equipamentos

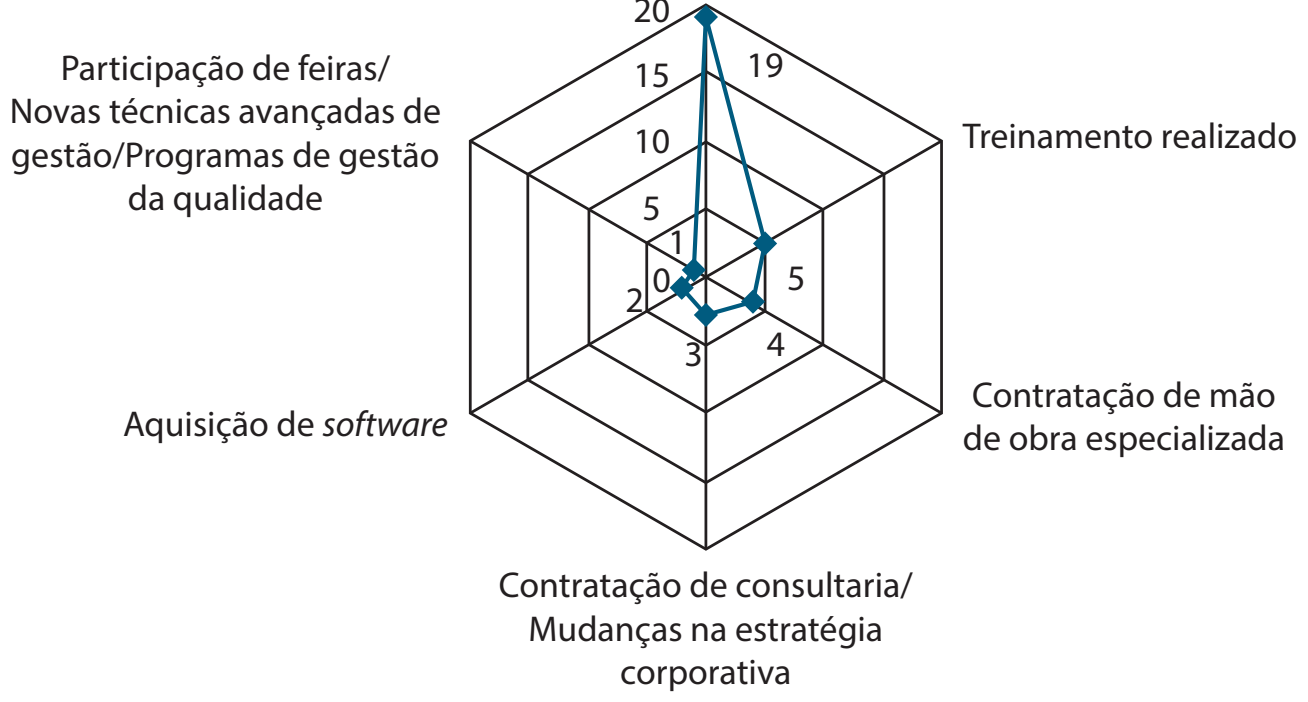

Fonte: Dos autores (2016)

Tal qual apresentado pelo Gráfico 2, as atividades "Aquisição de máquinas e equipamentos", "Treinamento realizado" e "Contratação de mão de obra especializa" destacam-se como as atividades inovativas mais empregadas pelas empresas, com claro predomínio da primeira. Este resultado segue consoante ao encontrado por Weersma e Silva Filho (2013), que, em seu estudo sobre os determinantes da inovação no setor têxtil do Ceará, constataram que as atividades inovativas mais relevantes para as empresas do setor têxtil daquele estado foram: “Aquisição de máquinas e equipamentos”,seguida de "Treinamento, introdução de mudanças na estratégia corporativa e introdução de novas técnicas avançadas de gestão" (WEERSMA; SILVA FILHO, 2013).

Entretanto, Néto e Teixeira (2011) fazem uma ressalva, destacando que, embora as empresas estejam melhorando seus processos com a compra ou o aluguel de maquinário moderno, a falta de investimentos em sistemas de gestão, certificação e softwares de gestão da produção colaboram para que a inovação apresentada pelas empresas se mostre incipiente (NÉTO; TEIXEIRA, 2011).

Ainda, referente às fontes de inovações implementadas no APL de confecções de Formiga, elas foram, em sua totalidade, uma novidade para as empresas, porém fruto de algo já existente no mercado. Tal fato reforça o argumento de Costa e Rocha (2009), segundo os quais, o setor têxtil e de confecções, a priori, é um consumidor de tecnologia.

Ratificando este argumento, Cunha (2013), ao analisar a inovação no setor têxtil e de confecção da cidade de Divinópolis/MG, inferiu, na ocasião, que a inovação se restringia às próprias empresas.

Outro tópico importante a ser frisado pela pesquisa são os motivos apontados como incentivo na busca pela inovação, conforme o Gráfico 3 . 


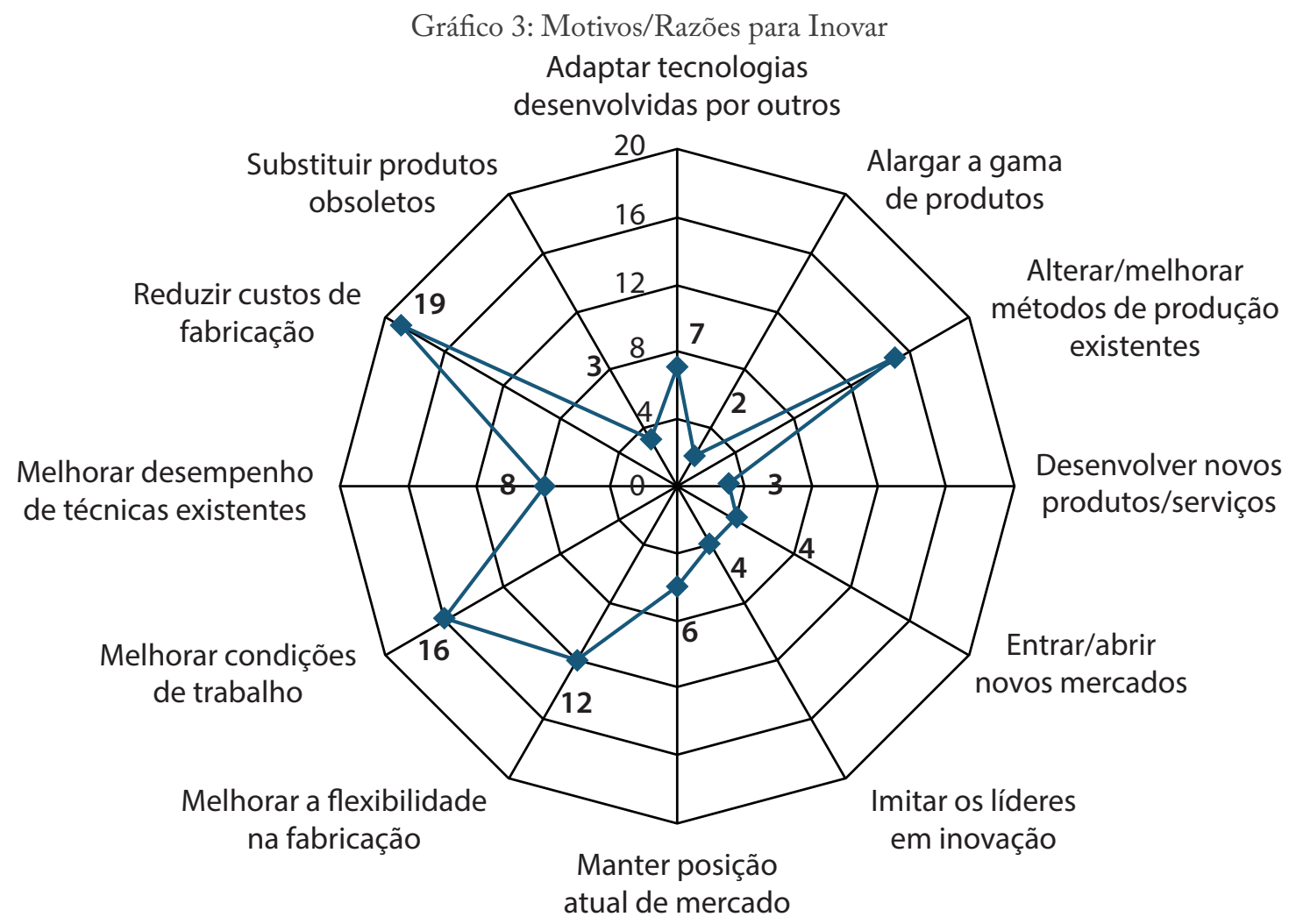

Fonte: Dos autores (2016)

Conforme o Gráfico 3, no presente estudo evidencia-se que, na busca por essa inovação e consequente competitividade, a principal ferramenta que os gestores pretendem lançar mão é a redução de seus custos de fabricação. Haja vista que este foi o principal motivo para se inovar, apontado por 19 empresas, $(55,88 \%)$. Outro motivo que se destacou foi a melhoria das condições de trabalho, apontado por $47 \%$ dos entrevistados. Tais resultados apresentam-se alinhados ao principal tipo de inovação apresentado pelas empresas, a inovação de processo, e com as principais atividades desenvolvidas para alcançar tais inovações, a aquisição de máquinas e equipamentos.
Percebe-se que, no entanto, MAIS QUE INOVAR, AS EMPRESAS BUSCAM MECANISMOS DE MELHORAR SUA EfICIÊNCIA E PERMANECER NO MERCADO.

Conforme é possível notar no Gráfico 4, não há grande motivação para se desenvolver uma marca ou ampliar o mercado consumidor atendido pelas empresas. Grande parte dos esforços inovativos apresenta como resultado o aumento da capacidade produtiva, apontado como principal resultado alcançado por $58,8 \%$ das empresas, seguido pela diminuição do tempo de produção $(47,05 \%)$. 


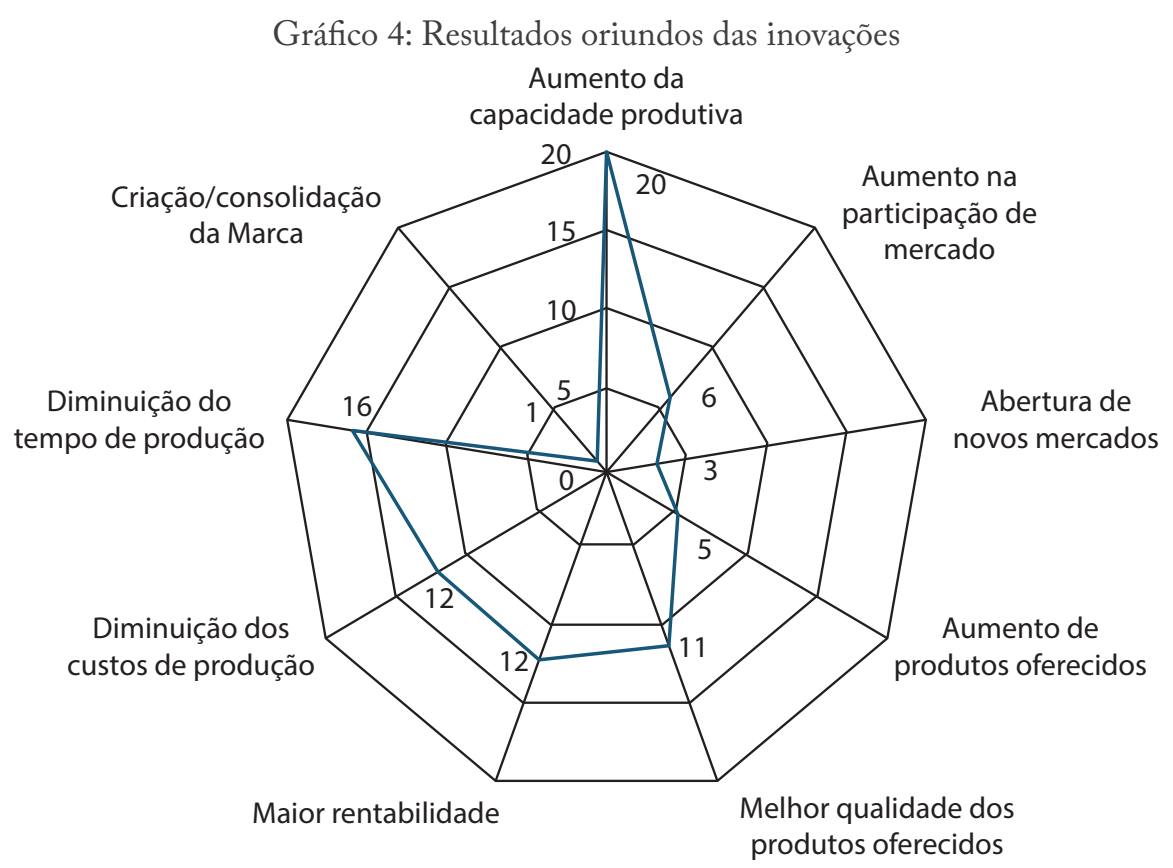

Fonte: Dos autores (2016)

No entanto, embora 19 dentre as empresas que realizaram algum tipo de inovação objetivassem a redução de seus custos de fabricação, apenas (12) alcançaram este objetivo.

Novamente os resultados obtidos se mostraram similares aos alcançados por Cunha (2013). Contudo, vale ressaltar que as empresas do APL de confecções de Formiga que inovaram, aumentaram sua produção em quase $12 \%$ a mais do que o verificado por Cunha (2013) nas empresas de Divinópolis: 86,96\% contra $75 \%$, respectivamente.

Outro ponto levantado pelo estudo diz respeito às dificuldades encontradas pelos empresários no processo de implementação da inovação, como pode ser observado na Tabela 2.

Tabela 2: Obstáculos que impediram/dificultaram o processo inovativo

\begin{tabular}{llcc}
\multicolumn{1}{c}{ Obstáculos } & Amostra & Empresas & Empresas Não \\
& Total & $(\%)$ & $\begin{array}{c}\text { Inovadoras } \\
\text { Inovadoras } \\
(\%)\end{array}$ \\
\hline Riscos econômicos excessivos & 50,00 & 60,87 & 27,27 \\
\hline Falta de mão de obra qualificada & 44,12 & 47,83 & 36,36 \\
\hline Dificuldade de adequação às normas & 17,65 & 13,04 & 27,27 \\
\hline Escassez de fontes de financiamento & 5,88 & 4,35 & 9,09 \\
\hline Falta de informação sobre mercados & 17,65 & 17,39 & 18,18 \\
\hline
\end{tabular}




\begin{tabular}{lccc}
\multicolumn{1}{c}{ Obstáculos } & $\begin{array}{c}\text { Amostra } \\
\text { Total }\end{array}$ & $\begin{array}{c}\text { Empresas } \\
\text { Inovadoras } \\
(\%)\end{array}$ & $\begin{array}{c}\text { Empresas Não } \\
\text { Inovadoras } \\
(\%)\end{array}$ \\
\hline Elevados custos de inovação & 41,18 & 43,48 & 36,36 \\
\hline Falta de informação sobre tecnologia & 8,82 & 8,70 & 9,09 \\
\hline Escassez de cooperação & 11,76 & 4,35 & 27,27 \\
\hline Falta de Serviços Técnicos Externos & 5,88 & 0,00 & 18,18 \\
\hline
\end{tabular}

Fonte: Dos autores (2016)

Quando analisados os obstáculos do processo inovativo, percebe-se que houve praticamente um consenso entre os 5 fatores mais indicados nas segmentações Amostra Total e Empresas Inovadoras, sendo eles: riscos econômicos excessivos (50\%) e (60,87\%), falta de mão de obraqualificada (44,12\%) e (47,83\%), elevados custos de inovação $(41,18 \%)$ e (43,48\%), falta de informações sobre mercados $(17,65 \%)$ e $(17,39 \%)$ e, por fim, dificuldade de adequação a padrões e normas com $(17,65 \%)$ e (13,04\%), respectivamente. Vale destacar que o principal contratempo associado à inovação foi riscos econômicos excessivos, atrelados a esse processo.

Já em relação às empresas não inovadoras, percebe-se que, além da mudança quanto à ordem dos principais obstáculos à inovação, houve também o surgimento entre os 5 mais indicados o tópico escassas possibilidades de cooperação com outras empresas e/ou instituições. Vale salientar que, para essa segmentação, os principais obstáculos apontados foram a falta de mão de obra qualificada, juntamente com os elevados custos de inovação.

É importante frisar que os obstáculos aqui levantados coincidem com os principais gargalos encontrados na indústria têxtil e de vestuário paulista, conforme o estudo de Carvalho e Serra (1999). Segundo os autores, naquela ocasião, a faltade recursos financeiros foi apontada como o principal obstáculo ao processo inovativo, porém outros fatores também estavam presentes, como mão de obra não qualificada e falta de cooperação (CARVALHO; SERRA, 1999).

Por fim, o estudo permite ainda a realização de um comparativo entre a inovação nas empresas do APL de Formiga e a inovação nas empresas em nível nacional, levantadas pela PINTEC 2011, conforme o Gráfico 5, a seguir. 
Gráfico 5: Comparativo de Inovação entre as empresas do APL de Formiga e a PINTEC 2011

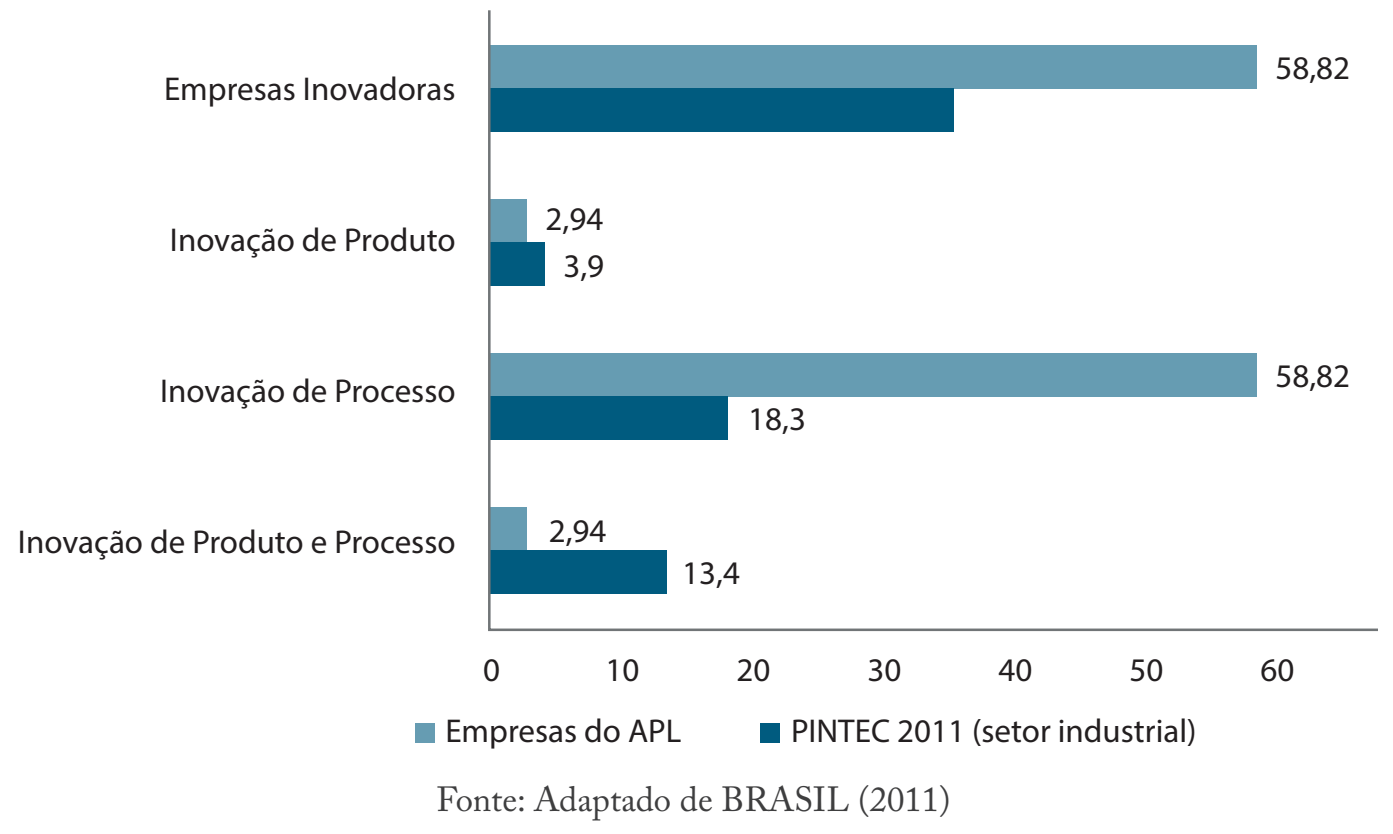

A pesquisa revela que a taxa de empresas inovadoras, na amostra,é superior à taxa de empresas inovadoras em âmbito nacional, conforme levantado pela PINTEC 2011 (BRASIL,2011).

Nota-se que o mesmo é observado em relação à inovação de processo, porém quando considerados os tópicos inovação de produto e também inovação de produto e processo, de forma conjunta, o estudo demonstra que a inovação de produto é incipiente nas empresas do APL de Formiga.

Embora tenha percebido a presença de inovação na maior parte da amostra (58,82\%), isso não permite inferir que há uma alta atividade inovativa nas empresas pesquisadas, como fica claro ao observar o estudo de Lucca (2014).

O referido estudo buscou identificar as inovações das empresas de pequeno porte do setor de confecções de São José do Rio Preto/SP. Para tanto, mediu o grau de inovação de sua amostra através de uma metodologia chamada Radar de Inovação, que analisa as empresas subdivididas em 13 escores diferentes.

Analisando o segmento de facção, por exemplo, o autor chegou a um grau de inovação global que revelou baixa atividade inovativa nas empresas. Porém, ao analisar apenas o escore Dimensão Plataforma (que diz respeito à infraestrutura, sistema de produção), os resultados apresentaram alta atividade inovativa (LUCCA, 2014).

Dito isto, a pesquisa de Lucca (2014) traz luz ao presente estudo, uma vez que o fato da inovação nas empresas do APL de Formiga ser superior à amostra nacional, não indica que essas empresas possuam um nível satisfatório de inovação a ponto de garantir a elas um desempenho superior no mercado. 


\section{CONSIDERAÇÕES FINAIS}

O presente estudo buscou analisar os tipos, características, fontes, motivações e os impactos relacionados à inovação, como objetivo de identificar os fatores que a determinam nas empresas participantes do APL de Confecções da cidade de Formiga/MG.

Analisando as características das empresas, foi possível identificar que a maioria das organizações é constituída por empresa de micro $(20,59 \%)$ ou de pequeno porte $(76,47 \%)$, que contam com até 49 funcionários e estão constituídas há mais de 10 anos no mercado. Em sua maior parte, as empresas se dedicam ao segmento de facção $(79,41 \%)$ e possuem como foco de atuação o mercado nacional.

O fato da concentração de facções explica, em parte, o fato de $32,35 \%$ das empresas pesquisadas não apresentarem qualquer iniciativa referente ao planejamento e/ou implantação de nenhum tipo de inovação, a incipiência da inovação de produto, bem como a ausência de inovação em marketing, haja vista que esse segmento de empresas não trabalha com a venda do produto final no varejo. A pesquisa revelou, ainda, que também é tímida a ocorrência da inovação de estrutura organizacional.

Tais características fundamentais nortearam não apenas o tipo de inovação adotado pelas empresas, mas alinharam as atividades de inovação desenvolvidas, destacando-se a Aquisição de máquinas e equipamentos, implementada por $55,9 \%$ das empresas, e seus objetivos, redução de seus custos de fabricação, destacado como objetivo final por $82,61 \%$ das empresas que fazem inovação.

Desta forma, percebe-se que as empresas, apesar de já estarem no mercado,em média, a bastante tempo, enxergam a inovação como meio para redução de seus custos de produção para garantir a competitividade e se manterem no mercado, dada a grande concorrência vivenciada pelas mesmas. Essas inovações disruptivas poderiam agregar valor, de fato, aos produtos não foram encontradas.

Basicamente, as empresas que inovaram o fizeram no âmbito da empresa e predominantemente utilizaram recursos próprios para fazê-lo.

Vale destacar, quanto aos obstáculos do processo inovativo, duas realidades. No que tange às empresas que realizaram inovação, as principais dificuldades estão associadas às finanças, aos riscos econômicos inerentes ao processo inovativo.Já para as organizações que não inovaram, as principais dificuldades estão relacionadas à falta de mão de obra qualificada e a pouco cooperação entre empresas.

Para pesquisas futuras, sugere-se aumentar a amostra das empresas, ampliando a análise para outros polos de confecções que possuam dinâmicas semelhantes na mesma região, mas que possibilitarão análises comparativas, bem como averiguar possíveis relações entre fatores de capacidade inovativa e desempenho das empresas em questão. 
DETERMINANTS OF

INNOVATION: AN

EMPIRICAL STUDY

IN THE TEXTILE

INDUSTRIES IN THE

CITY OF FORMIGA/

$M G$

\begin{abstract}
Thispaperpresents the analysis of textile firms that make up the confections' Local Productive Arrangement of the city of Formiga $(M G)$, sector that is characterized as the most dynamic of the city's economy. The study aims to identify the determinants of innovation in thosefirms by the means of a survey applied with their main managers. The results show that the practice of innovation in firms is understood as a way to reduce the production costs. Those evidences suggest that there is not an exploitation of the full innovative potential of organizations eat, although there are some signs, especially in the process of innovation, in most firms.
\end{abstract}

Keywords: Local Productive Arrangement. Innovation.

Competitiveness. Confection.

\section{REFERÊNCIAS}

ALVARENGA, Tiago Henrique de Paula et al. Conceitos, Definições e Características da Inovação no Setor Têxtil Brasileiro. 2014. Disponível em: <http://zip.net/bltxwc>. Acesso em: 07 ago. 2015.

\section{BRASIL. INSTITUTO BRASILEIRO DE GEOGRAFIA E ESTATÍSTICA - IBGE. \\ Cidades. 2015. Disponível em:<http://zip.net/ bbtxVY>. Acesso em: 18 nov. 2015.}

\section{. INSTITUTO BRASILEIRO DE GEOGRAFIA E ESTATÍSTICA - IBGE. Pesquisa de Inovação. 2011. Disponível em: <http://zip.net/bvtyrT>. Acesso em: 10 jan. 2015.}

\section{INSTITUTO DE PESQUISA}

ECONÔMICA APLICADA - IPEA. Pesquisa sobre atitudes empresariais para desenvolvimento e inovação. 2012. Disponível em: <http://zip.net/ bjtxXg>. Acesso em: 22 nov. 2015.

CARVALHO, Marly Monteiro de; SERRA, Neusa. Fontes de inovação: a cadeia têxtil paulista. Encontro Nacional de Engenharia de Produção, v. 19, 1999. Disponível em: <http://zip.net/bstyhq>. Acesso em: 09 fev. 2016.

\section{CONFEDERAÇÃO NACIONAL DA}

INDÚSTRIA - CNI. Indicadores de

Competitividade Na Indústria Brasileira. Brasilia. 2005. Disponível em: <http://zip.net/bhtx5V >.

Acesso em: 11 mar. 2015.

Indicadores de Competitividade na indústria brasileira: micro e pequenas empresas. Brasilia. 2006. Disponível em: <http://zip.net/ bmtxWV>. Acesso em: 14 jun. 2015.

COSTA, Ana Cristina Rodrigues da; ROCHA, Érico Rial Pinto da. Panorama da cadeia produtiva têxtil e de confecções e a questão da inovação. BNDES Setorial, n. 29, p. 159-202, 2009.

Disponível em: <http://zip.net/bptyHY>. Acesso em: 12 jun. 2015.

CUNHA, Maria dos Anjos Beirigo. Inovação no setor de confecção do vestuário: uma analise das características das indústrias de Divinópolis - MG. Centro Universitário UNA. 2013. 160 p. Disponível em: <http://zip.net/bstyhr>. Acesso em: 21 fev. 2016. 
DELGADO, I. G. Os setores farmacêutico, automotivo e têxtil na China, Índia e Brasil. Brasília: IPEA, 2015.

FERNANDES, Ricardo Lopes; CARIO, Silvio Antonio Ferraz. Características do processo inovativo da indústria têxtil de confecções de SC: uma avaliação do período 2000-2005. In: XI Encontro de Economia da Região Sul da Sul da Associação Nacional de Centros de Pós-Graduação em Economia ANPEC, 2008, Curitiba. Anais do In: XI Encontro de Economia da Região Sul da Sul da Associação Nacional de Centros de Pós-Graduação em Economia ANPEC, 2008. Disponível em: <http://zip.net/bttyL9>. Acesso em: 16 ago. 2015.

FORMIGA. Prefeitura Municipal. Turismo. 2015. Disponível em: <http://zip.net/bntx5B >. Acesso em: 30 nov. 2015.

FUNDAÇÃO JOÃO PINHEIRO (FJP). Dataviva. Disponível em: <http://pt.dataviva.info/>. Acesso em: 09 jan. 2016.

ALBUQUERQUE JUNIOR, Edmilson Pinto de Albuquerque; LIMA, Bruno Chaves Correia; LAZARO, José Carlos. Inovação, Estratégia e Competitividade nas Empresas Brasileiras: uma Investigação Inicial sobre Atividades Inovativas e Impactos conforme o PINTEC 2008. RAUnP, v. 3, n. 2, p. 25-38, 2011. Disponível em:<http://zip.net/ bytytm>. Acesso em: 16 jul. 2015.

LASTRES, Helena et al. Desafios e oportunidades da era do conhecimento. São Paulo em Perspectiva, v. 16, n. 3, p. 60-66, 2002. Disponível em: <http://zip.net/ bytytn>. Acesso em: 07 jul. 2015.

LUCCA, Lucio Flávio. Características de inovação em diferentes segmentos da confecção. Cadernos de Inovação, p. 147. Disponível em: <http://zip.net/ bctx2Y>. Acesso em: 05 fev. 2016.

NÉTO, Ana Teresa Da Silva; TEIXEIRA, Rivanda Meira. Mensuração do Grau de Inovação de Micro e Pequenas Empresas: Estudo em Empresas da Cadeia Têxtil-Confecção em Sergipe. Review of Administration and Innovation - RAI v. 8, n. 3 , 7 nov. 2011. Disponível em: <http://zip.net/bhtx5W>. Acesso em: 16 jan. 2016.
ORGANIZAÇÃO PARA COOPERAÇÃO E DESENVOLVIMENTO ECONÔMICO - OCDE. Manual de Oslo: proposta de diretrizes para coleta e interpretação de dados sobre inovação tecnológica. Brasília, 2005. DF: FINEP. Disponível em: <http://zip. net/bltxwd>. Acesso em: 09 jun. 2015.

QUANDT, Carlos Olavo. Redes de cooperação e inovação localizada: estudo de caso de um arranjo produtivo local DOI: 10.5773/rai. v1i1. 674. RAI - Revista de Administração e Inovação, v. 9, n. 1, p. 141-166, 2012. Disponível em: <http://zip.net/ bbtxV0>. Acesso em: 19 jun. 2015.

SERVIÇO BRASILEIRO DE APOIO ÀS MICRO E PEQUENAS EMPRESAS - SEBRAE. 99

Soluções Inovadoras. 2009. Disponível em: <http:// zip.net/brtx4Z> Acesso em: 21 nov. 2015.

Critérios e conceitos para classificação de empresas. 2015. Disponível em: <http://zip.net/ bctx $2 Z>$. Acessado em: 11 maio. 2015.

SOUSA, Jonilto Costa. Processo de inovação em abordagem multidisciplinar. GESTÃO. Revista

Eletrônica de Gestão Organizacional, v. 4, n. 2, 2006. Disponível em: <http://zip.net/bqty0W >. Acesso em: 18 jul. 2015.

TEIXEIRA, Paulo Sérgio. Dinâmica Sócio espacial da Indústria de Confecções de Formiga (MG). 2012. 62f. Monografia (Conclusão de curso) - Universidade Federal de Minas Gerais, Departamento de Geografia, Belo Horizonte, 2012.

WEERSMA, Menno Rutger; SILVA FILHO, José Carlos da. Percepção de Fatores Determinantes da Inovação em Empresas do Setor Textil. altec2013.org p. 1-14, 2013. Disponível em: <http://zip.net/bgtx1h>. Acesso em: 27 fev. 2016.

\section{WORLD ECONOMIC FORUM. The Global} Competitiveness Report 2014-2015. Disponível em: <http://zip.net/bjtxXh>. Acesso em: 17 jun. 2015.

Data de recebimento: 27/05/2016

Data de aprovação: 13/12/2016 


\section{APÊNDICEA - Questionário Determinante para a inovação do Arranjo Produtivo Local (APL) de Confecções da cidade de Formiga/MG}

SEÇÃO 1 - Caracterização da empresa e processo produtivo

Empresa:

Segmento: ( ) Confecção （）Facção （ ) Private Label

Anodefundação: $\mathrm{N}^{\circ}$ defuncionários:

Endereço:

Classificação da empresa quanto ao tamanho:

Entrevistado: Cargo:

Quantos anos de experiência em gerenciamento?

1.1 Constituição do capital da empresa: (A) na ocasião de sua fundação e (B) nos últimos doze meses:
A- ( ) Capital Próprio ( ) Capital de Terceiros ( ) Ambos
B- ( ) Capital Próprio ( ) Capital de Terceiros ( ) Ambos

1.2 Abrangência de atuação da empresa:

( )Municipal ( )Regional ( )Nacional

1.3 Faturamento Bruto anual:

（）Até 100.000,00（）Até 300.000,00（）Até 500.000,00（）Acima de 500.000,00

1.4 Qual a principal dificuldade encontrada na gestão da empresa nos últimos doze meses?

( ) Mão de obra qualificada

( ) Acesso a capital de giro

( ) Venda da produção

( ) Pagamento dos empréstimos contraídos

( ) Falta de linha de crédito específico para o negócio 
SEÇÃO 2 - Elementos de inovação: identificação dos tipos e fontes de inovação

\begin{tabular}{|c|c|c|c|}
\hline & & Sim & Não \\
\hline 2.1 - Tipo de & De produto & & \\
\hline inovação: & De processo & & \\
\hline empresa introduziu & De marketing & & \\
\hline $\begin{array}{c}\text { novidade no mercado } \\
\text { em termos de: }\end{array}$ & De estrutura organizacional & & \\
\hline
\end{tabular}

\begin{tabular}{|c|c|c|c|}
\hline & & Sim & Não \\
\hline 2.2 - Característica & $\begin{array}{l}\text { Algo novo para o mercado internacional ou } \\
\text { nacional. }\end{array}$ & & \\
\hline $\begin{array}{c}\text { Esta inovação de } \\
\text { produto / processo / }\end{array}$ & $\begin{array}{l}\text { Algo novo para o mercado nacional, mas existente } \\
\text { no mercado internacional. }\end{array}$ & & \\
\hline $\begin{array}{c}\text { marketing / estrutura } \\
\text { organizacional é: }\end{array}$ & $\begin{array}{l}\text { Algo novo para a empresa, mas que já existe no } \\
\text { mercado. }\end{array}$ & & \\
\hline
\end{tabular}

\begin{tabular}{|c|c|}
\hline \multirow{12}{*}{$\begin{array}{l}2.3 \text { - Fontes de } \\
\text { inovação: Esta } \\
\text { inovação de } \\
\text { produto / processo / } \\
\text { marketing / estrutura } \\
\text { organizacional é } \\
\text { resultado de: }\end{array}$} & ( ) Aquisição de software. \\
\hline & ( ) Aquisição de máquinas e equipamentos. \\
\hline & ( ) Atividade de P\&D realizada. \\
\hline & ( ) Aquisição externa de P\&D. \\
\hline & ( ) Treinamento realizado. \\
\hline & ( ) Participação em feiras, conferências, seminários etc. \\
\hline & ( ) Contratação de mão de obra especializada. \\
\hline & ( ) Contratação de consultoria. \\
\hline & ( ) Introdução de mudanças na estratégia corporativa. \\
\hline & ( ) Introdução de novas técnicas avançadas de gestão. \\
\hline & ( ) Introdução de programas de gestão da qualidade. \\
\hline & $\begin{array}{l}\text { ( ) Parcerias com Universidades; Institutos de Pesquisa; Centros de } \\
\text { capacitação profissional. }\end{array}$ \\
\hline
\end{tabular}


SEÇÃO 3 - Motivações para inovar

\begin{tabular}{|c|c|}
\hline \multirow{13}{*}{$\begin{array}{c}3.1 \text { - Razões } \\
\text { ou causas que } \\
\text { incentivaram a } \\
\text { empresa a inovar: }\end{array}$} & ( ) Desenvolver novos produtos e serviços. \\
\hline & ( ) Alterar ou melhorar os métodos de produção existentes. \\
\hline & ( ) Imitar os líderes em inovação. \\
\hline & $\begin{array}{l}\text { ( ) Adaptar as tecnologias desenvolvidas por outros às necessidades da } \\
\text { empresa. }\end{array}$ \\
\hline & ( ) Melhorar o desempenho de técnicas existentes. \\
\hline & ( ) Substituir produtos obsoletos. \\
\hline & ( ) Alargar a gama de produtos. \\
\hline & ( ) Manter posição atual de mercado. \\
\hline & ( ) Entrar/abrir novos mercados. \\
\hline & ( ) Melhorar a flexibilidade na fabricação. \\
\hline & ( ) Reduzir custos de fabricação. \\
\hline & ( ) Melhorar as condições de trabalho. \\
\hline & ( ) Outras: \\
\hline
\end{tabular}

SEÇÃO 4 - Impacto das inovações:

\begin{tabular}{|c|l|}
\hline \multirow{4}{*}{$\begin{array}{c}\text { 4.1 - Quais setores } \\
\text { que mais tem se } \\
\text { beneficiado pelas }\end{array}$} & $($ ) Setor de RH \\
\cline { 2 - 2 } $\begin{array}{c}\text { inovações realizadas } \\
\text { na empresa? }\end{array}$ & $($ ) Setor Financeiro \\
\cline { 2 - 2 } & $($ ) Setor de Marketing \\
\cline { 2 - 2 } & $($ ) Setor de Vendas \\
\hline
\end{tabular}




\begin{tabular}{|c|c|}
\hline \multirow{13}{*}{$\begin{array}{r}\text { processo de inovaç } \\
\text { para a empresa? }\end{array}$} & ( ) Aumento da capacidade produtiva. \\
\hline & ( ) Aumento na participação de mercado. \\
\hline & ( ) Abertura de novos mercados. \\
\hline & ( ) Aumento no número de produtos oferecidos. \\
\hline & ( ) Melhoria na qualidade dos produtos oferecidos. \\
\hline & ( ) Aumento da rentabilidade. \\
\hline & ( ) Diminuição dos custos de produção. \\
\hline & ( ) Diminuição do tempo de produção. \\
\hline & ( ) Patente de invenção. \\
\hline & ( ) Patente de modelo de utilidade. \\
\hline & ( ) Registro de desenho industrial. \\
\hline & ( ) Criação ou consolidação da Marca. \\
\hline & Outras: \\
\hline
\end{tabular}




\begin{tabular}{|c|c|}
\hline \multirow{9}{*}{$\begin{array}{l}5.1 \text { - Identifique } \\
\text { as fontes de } \\
\text { recursos utilizadas } \\
\text { no processo de } \\
\text { inovação: }\end{array}$} & $\begin{array}{l}\text { ( ) Incentivo fiscal Lei de Informática (redução de IPI para empresas que } \\
\text { investem em P\&D). }\end{array}$ \\
\hline & $\begin{array}{l}\text { ( ) Subvenção econômica (compartilhamento de custos entre empresa e } \\
\text { Estado) à P\&D e à inserção de pesquisadores. }\end{array}$ \\
\hline & $\begin{array}{l}\text { ( ) Financiamento a projetos de P\&D e inovação tecnológica sem parceria } \\
\text { com universidades ou institutos de pesquisa }\end{array}$ \\
\hline & $\begin{array}{l}\text { ( ) Financiamento a projetos de P\&D e inovação tecnológica em parceria } \\
\text { com universidades ou institutos de pesquisa. }\end{array}$ \\
\hline & $\begin{array}{l}\text { ( ) Financiamento exclusivo para a compra de máquinas e equipamentos } \\
\text { utilizados para inovar. }\end{array}$ \\
\hline & $\begin{array}{l}\text { ( ) Bolsas oferecidas pelas fundações de amparo à pesquisa e RHAE/ CNPq } \\
\text { (Programa de formação de Recursos Humanos em Áreas Estratégicas) para } \\
\text { pesquisadores em empresas. }\end{array}$ \\
\hline & ( ) Aporte de capital de risco. \\
\hline & ( ) Linha específica de crédito (FINEP, BNDES, BDMG, entre outras). \\
\hline & ( ) Outros incentivos fiscais: \\
\hline
\end{tabular}

\section{SEÇÃO 6 - Dificuldades de se inovar}

\begin{tabular}{|c|c|}
\hline \multirow{9}{*}{$\begin{array}{c}6.1 \text { - Identifique } \\
\text { as dificuldades, } \\
\text { problemas ou } \\
\text { obstáculos que } \\
\text { impediram/ } \\
\text { dificultaram o } \\
\text { processo inovativo } \\
\text { de sua empresa: }\end{array}$} & ( ) Riscos econômicos excessivos. \\
\hline & ( ) Falta de pessoal qualificado. \\
\hline & ( ) Dificuldade para se adequar a padrões, normas e regulamentações. \\
\hline & ( ) Escassez de fontes apropriadas de financiamento. \\
\hline & ( ) Falta de informação sobre mercados. \\
\hline & ( ) Elevados custos da inovação. \\
\hline & ( ) Falta de informação sobre tecnologia. \\
\hline & ( ) Escassas possibilidades de cooperação com outras empresas/instituições. \\
\hline & ( ) Escassez de serviços técnicos externos adequados. \\
\hline & ( ) Outros: \\
\hline
\end{tabular}




\section{SOBRE OS AUTORES}

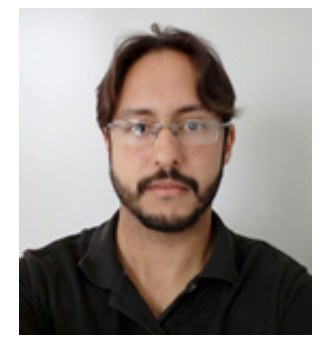

\section{Bruno César Melo}

\section{Moreira}

Possui graduação em Economia pela Universidade Federal de Minas Gerais (2006), mestrado em Economia e Finanças (2008) e doutorado em Administração (2012) pela Universidade Federal de Santa Catarina. Participa de grupos de pesquisa sobre Desenvolvimento Regional, APLs e Inovação e Finanças Comportamentais. Tem experiência na área de Educação a Distância, atuando de 2009 a 2011 como Supervisor de Curso e Subcoordenador deTutoria do Curso de Graduação em Administração na modalidade a Distância da UFSC. Atualmente é professor do Instituto Federal de Minas Gerais IFMG, Campus Formiga, onde exerce o cargo de Secretário de Extensão, Pesquisa e Pós-graduação e de Editor-Chefe da ForScience: Revista Científica do IFMG.

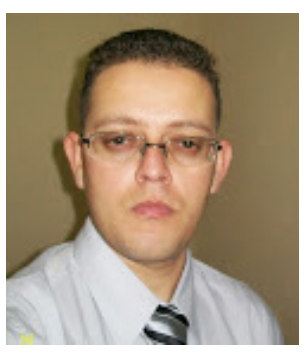

\section{Everaldo Hipólito da Silva}

Tecnólogo em Gestão Financeira, graduado pelo InstitutoFederaldeEducação, CiênciaeTecnologiadeMinas Gerais (IFMG),Especialista em Gerenciamento de Projetos, pela Pontifícia Universidade Católica de Minas Gerais (PUCMinas). Foi membro do Núcleo de Pesquisa em Tecnologia e Desenvolvimento Empresarial do Instituto Federal de Educação, Ciência e Tecnologia de Minas Gerais (IFMG). Atualmente é servidor público municipal, lotado na autarquia Serviço Autônomo de Água e Esgoto (SAAE), na cidade de Formiga (MG).

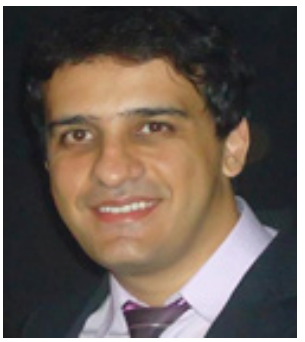

Lélis Pedro de Andrade

Possui graduação e mestrado em Administração/Finanças pela Universidade Federal de Lavras (UFLA), doutorado em Administração/Finanças pelaUniversidade FederaldeMinas Gerais(UFMG), com período sanduíche em Alberta School of Business,UniversityofAlberta,Canadá.Desde 2008, é professor no Instituto Federal de Minas Gerais IFMG/Campus Formiga.Tem experiência naárea de Administração, especialmente nos seguintes temas: Administração Financeira, Finanças Corporativas e Governança Corporativa.

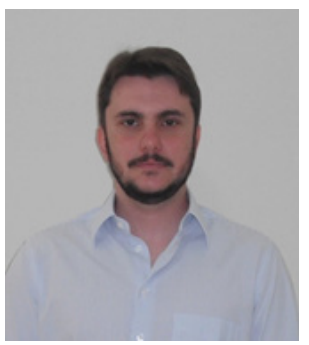

\section{Adriano Olímpio Tonelli}

Bacharel em Ciência da Computação e Mestre em Administração pela Universidade Federal de Lavras (UFLA). Ao longo de nove anos, atuou nas áreas de inovação, gestão do conhecimento em organizações, governança de tecnologia da informação no setor público, sistemas de informação e programação. Possui experiência em gestão de prospecção e de projetos de PD\&I (1 ano), coordenação de cursos técnicos ( 2 anos), docência (5 anos), Ensino a Distância (5 anos) e desenvolvimento de projetos de pesquisa e extensão (8 anos). Atualmente, é doutorando em Administração pela UFLA, professor do Instituto Federal de Educação, Ciência e Tecnologia de Minas Gerais (IFMG), campus Formiga, e pesquisador do Polo de Inovação EMPRABII Formiga. 
